\title{
TRANSPORTE PÚBLICO DO MUNICÍPIO DE NATAL: ASPECTOS DE PARAFISCALIDADE DO CASO SETURN
}

\author{
M. D. M. SILVA* e L. F. L. G. COSTA \\ Instituto Federal de Educação, Ciência e Tecnologia do Rio Grande do Norte \\ manoel.silva@ifrn.edu.br
}

Artigo submetido em julho/2015 e aceito em novembro/2015

DOI: $10.15628 /$ holos.2015.2310

\section{RESUMO}

A proposta deste trabalho é compreender como os aspectos da gestão parafiscal do Sindicato das Empresas de Transporte Urbano de Passageiros do Município do Natal - SETURN contribuem para a eficiência do transporte público e para a melhoria da mobilidade urbana, visando contribuir na qualidade de vida da população local. A pesquisa foi desenvolvida no Sindicato, baseada no estudo de caso, por meio de entrevista semiestruturada, onde foram feitas análises, com o objetivo de descrever a situação do transporte coletivo relativo à eficiência. Como resultado observouse que ela fica comprometida, uma vez que os automóveis particulares disputam o mesmo espaço nas vias, juntamente com os transportes coletivos, impedindo assim, agilidade nas viagens. Observa-se também, a necessidade de investimento na infraestrutura, essa por parte do poder público ou em parceira com o Sindicato representante das empresas.

PALAVRAS-CHAVE: Transporte público, Parafiscalidade, Terceiro setor, Eficiência.

\section{PUBLIC TRANSPORT OF THE COUNTY OF NATAL: PARAFISCALIDADE ASPECTS OF THE CASE SETURN}

\begin{abstract}
The purpose of this study is to understand how aspects of "parafiscal" management of the Sindicato das Empresas de Transporte Urbano de Passageiros do Município do Natal - SETURN contribute to the efficiency of public transport and the improvement of urban mobility, aiming to contribute to the population's quality of life local. The research was based on SETURN case, through semistructured interview, which analyzes were performed in
\end{abstract}

order to describe the situation of public transport on the efficiency. As a result it is compromised, because private cars vying for the same space on the roads, along with public transport, thus preventing flexibility in travel. It is also observed the need for investment in infrastructure, this by the government or in partnership with the SETURN representative companies

KEYWORDS: Public transportation, Parafiscal taxability, Third sector, Efficiency. 


\section{INTRODUÇÃO}

Com o crescimento populacional e o desenvolvimento das cidades, diversos problemas surgiram, dentre eles, o transporte, o trânsito e a mobilidade urbana, principalmente nos países em desenvolvimento.

No Brasil, o transporte público terrestre é feito por meio de ônibus, trens e metrôs, que, apesar de ser um serviço prestado pelo setor privado, em alguns casos, ainda é muito precário em relação ao esperado pela população que dele depende para sua locomoção. Esse setor vem sofrendo os impactos da chamada Era Pós-industrial, que alterou a vida das pessoas, das organizações e da sociedade de um modo geral.

Portanto, nas últimas décadas vive-se uma verdadeira crise no trânsito das grandes cidades ou metrópoles. Para Bodmer e Porto (2004), são de fundamental importância pesquisas que venham oportunizar condições, na expectativa de encontrar-se uma solução para recuperar o setor, visando amenizar transtornos que são gerados à população e que provocam perdas de tempo que poderia ser usado na produtividade, contribuindo para o desenvolvimento social.

Diante desse quadro, o trabalho descreverá o transporte público, por ônibus, regulamentado no Brasil, que vem sofrendo, nos últimos anos, com a queda na participação do uso do transporte coletivo nos deslocamentos urbanos, dando espaço ao fortalecimento do transporte individual. Isso acontece por causa da expansão automobilística, a qual deve ser fator de preocupação, tanto das empresas operadoras do sistema como do poder público como gestor da estrutura urbana (BODMER, PORTO 2004).

O Estado do Rio Grande do Norte, fazendo parte desse cenário, também não é diferente, principalmente nas cidades com maior desenvolvimento econômico e o crescimento populacional, levando em consideração a diminuição da desigualdade social que vem sendo desenvolvida através das políticas públicas nos últimos anos no Brasil.

Diante disso, nota-se que muitos dos cidadãos têm adquirido seu meio de transporte próprio gerando assim, um congestionamento nas cidades. Para Aragão et al (2004) no que tange, especialmente, ao transporte urbano de passageiros, trata-se de um setor em franca crise.

Como uma das capitais que compõem o território brasileiro, Natal vem sofrendo a mesma consequência, com o crescimento populacional e o uso desordenado do solo, tendo em vista que a cidade, nos últimos anos, tanto de forma horizontal, quanto na forma vertical, tem se destacado em empreendimentos comerciais e habitacionais, os quais concentram-se, principalmente, no centro da cidade. De acordo com Queiroz et al (2009), o processo de verticalização da cidade ocorreu, entre os anos de 2000 a 2007, quando os estrangeiros começaram a fazer grandes investimentos imobiliários. Nesse mesmo período, surge a discussão sobre o Plano Diretor, que se confirmou em 2007, no propósito de impor limite a esse crescimento.

O crescimento vertical traz, para os centros urbanos, maiores concentrações populacionais, levando em consideração, o fato de o espaço ser relativamente pequeno. Por outro lado, traz qualidade e sustentabilidade para o desenvolvimento econômico e social, consequentemente, maior intensificação no trânsito, podendo assim ocasionar diversos congestionamentos.

Com o congestionamento, o transporte público tende a se tornar mais lento, prejudicando os seus usuários e, consequentemente, toda a cadeia produtiva, tendo em vista que o transporte, 
seja ele de passageiros e/ou de cargas, é a variável que norteia o desenvolvimento econômico de toda sociedade (BOWERSOX, CLOSS 2001).

A capital do Estado do Rio Grande do Norte atualmente tem uma frota de 320.081 veículos que trafegam em suas vias. Desses, 2.411 são ônibus (IBGE, 2012) que fazem parte do sistema de transporte coletivo para atender a população de Natal e até mesmo da Grande Natal, tendo em vista que a área Metropolitana, em seu contexto, pode ser atendida, de forma harmônica e consensual, com base nos princípios legais, por essa frota.

Portanto, o trabalho busca compreender como os aspectos da gestão parafiscal do Sindicato das Empresas de Transporte Urbano de Passageiros do Município do Natal - SETURN contribui para a eficiência do transporte público do município do Natal/RN, onde fará a descrição das condições do transporte público da cidade, averiguando os padrões de funcionamento, com relação ao desenvolvimento e à eficiência do transporte.

Em virtude da dificuldade enfrentada pela população de Natal, no trânsito e no transporte público, surge o interesse em identificar os problemas e apresentar possíveis alternativas que possam contribuir para amenizar essa situação que tende a aumentar.

As instituições acadêmicas têm se preocupado em identificar problemas que afetam a população de forma geral ou de uma determinada região que limita o equilíbrio sustentável, impedindo assim, o desenvolvimento social. Para tanto, as pesquisas são extremamente necessárias, e darão aos órgãos gestores e operadores condições de implementar e implantar políticas públicas que, direta ou indiretamente, oferecerá uma estrutura social, capaz de atender e priorizar serviços em determinados setores da economia que são de fundamental importância para melhorar a qualidade de vida das pessoas, neste caso, o transporte público.

Como se pode observar, a participação social, atualmente, tem sido fator preponderante nas decisões governamentais que tem recorrido ao setor privado com o objetivo de tocar empreendimentos em parceira com organizações do terceiro setor. Isso significa maior probabilidade em atingir suas metas e gerar resultados satisfatórios, que de acordo com Tomei e Fortunato (2008), oferece maior controle e transparência nas ações governamentais. Com isso, toda a sociedade sairá ganhando.

\section{REFERENCIAL TEÓRICO}

Diante desse cenário, ultimamente, o poder público tem recorrido à sociedade civil organizada, com o propósito de criar oportunidades para a participação de todos os segmentos sociais na formulação das políticas públicas que possam atenuar o desequilíbrio que sofre a estrutura pública.

Nas últimas décadas a sociedade brasileira vem se organizando, no intuito de encontrar soluções para os problemas que afetam o dia a dia das pessoas. No entanto, não tem sido fácil superar as dificuldades, tendo em vista a diversidade e os desafios que surgem a cada momento da evolução, aumentando assim, a demanda social. Essa participação vem sendo construída ao longo dos anos, e se consolidou ainda mais com a Constituição de 1988. 


\subsection{TRANSPORTE PÚBLICO: ATUAÇÃO DO TERCEIRO SETOR E SUA LESGISLAÇÃO}

Organização Social - OS é uma entidade de pessoas jurídicas de direito privado, sem fins lucrativos e é outorgada pela administração pública a exercer atividades de interesse público. Esse título possibilita à organização receber recursos orçamentários e bens públicos, sendo esses dirigidos ao ensino, à pesquisa científica, ao desenvolvimento tecnológico, à proteção e preservação do meio ambiente, à cultura e à saúde, observando, ainda, os requisitos contidos na Lei federal no 9.637 de 15 maio de 1998, que estabelece que o Poder Executivo pode qualificar como organizações sociais. A Legislação Federal representa apenas um modelo para que os Estados e Municípios, cada um possa legislar a respeito dos serviços que entenderem necessários e firmem contrato de gestão entre o poder público e entidade qualificada como organização social. Portanto, para todos os efeitos legais, as entidades qualificadas como organizações sociais são declaradas como entidades de interesse social e utilidade pública.

Já as Organizações da Sociedade Civil de Interesse Público - OSCIP, instituída pela Lei no 9.790 de março de 1999, é também uma entidade de pessoas jurídicas de direito privado, sem fins lucrativos, desde que os respectivos objetivos sociais sejam de dedicação às atividades nele previstas, configura-se mediante a execução direta de projetos, programas, planos de ações correlatas, por meio da doação de recursos físicos, humanos e financeiros, ou ainda pela prestação de serviços intermediários de apoio a outras organizações sem fins lucrativos e a órgãos do setor público que atuem em áreas afins. Considera-se sem fins lucrativos a pessoa jurídica de direito privado que não distribui, entre os seus sócios ou associados, conselheiros, diretores, empregados ou doadores, eventuais excedentes operacionais, brutos ou líquidos, dividendos, bonificações, participações ou parcelas do seu patrimônio, auferidos mediante o exercício de suas atividades, e que os apliquem integralmente na consecução do respectivo objeto social.

Fica instituído o Termo de Parceria, assim considerado o instrumento passível de ser firmado entre o Poder Público e as entidades qualificadas como Organizações da Sociedade Civil de Interesse Público, destinado à formação de vínculo de cooperação entre as partes.

O setor público, diante do universo pelo qual se faz necessário atender as demandas oriundas da sociedade, no campo social, e tendo em vista a escassez de recursos para a prestação de serviços com qualidade, tem firmado parcerias com o setor privado e as organizações sociais.

Onde Farah (2001, p. 126) relata que:

No final da década de 1980 e início dos anos 1990, já sob o impacto da crise fiscal, a escassez de recursos passou a ser uma questão central, ao limitar a capacidade de resposta do Estado às demandas crescentes na área social. Assim, ao lado da preocupação com a democratização dos processos e com a equidade dos resultados, foram introduzidas na agenda preocupações com a eficiência, a eficácia e a efetividade da ação estatal, assim como com a qualidade dos serviços públicos.

Portanto, a participação social na formulação das políticas públicas de governos vem se tornando cada vez mais evidente, uma vez que o poder público percebe a necessidade do envolvimento social através das organizações, no sentido de facilitar a identificação de toda uma problemática existente. 
Diante dessa expectativa surge o conceito das parcerias, que tem por finalidade agregar esforços dentre vários segmentos da sociedade, com o propósito de melhorar a qualidade dos serviços que, inicialmente, seria de competência do setor público, que agora vem delegando ao setor privado a operacionalização das políticas públicas.

Como a sociedade vive uma constante evolução, sempre surgem novas palavras, mas algumas palavras causam estranhezas, não porque elas não existam, mas pelo pouco emprego, até mesmo no universo acadêmico. Nas universidades, ambiente de pesquisas e divulgação do conhecimento, os conceitos demandam certo tempo para que possam fazer parte do cotidiano das pessoas.

Um exemplo é a parafiscalidade que teve seu surgimento na Itália e na França sob os olhares de doutrinadores práticos que atribuíam ao Estado o poder de tributar, e em contrapartida, a relação de troca, ou seja, prestação serviços à sociedade, cidadão contribuinte (FERNANDES 2005), onde órgãos corporativos receberam o direito de tributar livremente, impondo, as contribuições necessárias para a manutenção das suas atividades.

As contribuições compulsórias são arrecadadas pelas entidades de classe como sindicatos, conselhos, etc. de direito privado sem fins lucrativo. Portanto são caracterizadas como parafiscalidade, e devem ser aplicadas em assistência ou ao ensino das categorias profissionais.

Segundo Borges (2011, p. 2):

Em regra, a doutrina sempre entendeu os serviços sociais autônomos como entidades com criação autorizada por lei, com personalidade de direito privado, sem fins lucrativos, para ministrar assistência ou ensino a certas categorias sociais ou profissionais, vinculadas ao sistema sindical, mantidas por contribuições paraficais ou dotações orçamentárias.

Para tanto, cabe ao poder público controlar e fiscalizar as ações executadas por essas entidades, através da participação de outras organizações, criando assim, parcerias setoriais entre o setor público, privado e o terceiros setor, este último onde estão inseridas as organizações sem fins lucrativos.

No Brasil, a parafiscalidade é inserida no ordenamento jurídico, sem grandes preocupações, provocando dessa forma, vários desentendimentos ou indefinições que ainda são vistas hoje, por ser uma contribuição que contempla a natureza tributária. Entretanto, observa-se que a partir da Constituição de 1946, a parafiscalidade recebeu várias mudanças, acompanhando a evolução do Direito Tributário brasileiro. Portanto, o termo parafiscalidade não teve tanta acepção de utilização no Brasil, segundo (FERNANDES 2005).

Para tanto, poder público tem delegado ao setor privado à capacidade de tributar. A parafiscalidade representa uma descentralização administrativa motivada por mudanças estatais, que transfere o direito de arrecadar receitas para desenvolver atividades específicas, como é o caso do SETURN, que realiza a prestação de serviços de transporte público na da cidade do Natal.

Portanto, está facultada às contribuições sindicais, caracterizada pela vedação de qualquer tipo de interferência por parte do poder público na organização sindical. Para tanto, criou-se no Brasil as contribuições especiais para seguridade social e sindical, que recebe o nome de parafiscalidade (FERNANDES 2005). 
Tanto o setor público quanto privado desenvolvem suas ações baseadas em planejamentos. E dentro de um bom planejamento, a logística é essencial. Portanto ela está presente em toda atividade desenvolvida pela sociedade, mesmo sem a pessoa se dar conta. No entanto, a logística é o meio pelo qual se monta estratégia para se atingir determinados objetivos, desde a matériaprima até o produto final, seja ele tangível ou intangível (BOWERSOX, CLOSS 2001).

A responsabilidade da logística está diretamente relacionada com a disponibilidade dos produtos tangíveis e intangíveis, mantendo a qualidade e o menor custo para atender a expectativa dos clientes, tendo por princípio, garantir a quantidade certa, no local certo e no tempo certo, completando assim, a satisfação dos usuários ou clientes. Portanto, o objetivo central da logística é atingir um nível desejado de serviço ao cliente pelo menor custo possível (BOWERSOX, CLOSS 2001).

De acordo com Bowersox e Closs (2001, p. 23):

[...] a logística de uma empresa é um esforço integrado com o objetivo de ajudar a criar valor para o cliente pelo menor custo total possível. A logística existe para satisfazer às necessidades do cliente, facilitando as operações relevantes de produção e marketing. Do ponto de vista estratégico, os executivos de logística procuram atingir uma qualidade predefinida de serviço ao consumidor por meio de competência operacional que representa o estada-da-arte. O desafio é equilibrar as expectativas de serviços e os gastos de moldo a alcançar os objetivos do negócio.

$\mathrm{Na}$ formulação de preços de transporte, os autores acima citados observam três tópicos. Primeiramente a economia do setor, e em segundo lugar a estrutura de custos decorrente das despesas, e por último, as taxas de fretes que são fundamentais para os preços cobrados aos clientes. Isso se refere aos transportes de cargas.

Quanto ao transporte de passageiros, o Manual de Bus Rapid Transt (BRT) - Transporte Rápido por Ônibus, descreve que "o cálculo dos custos de operação e do faturamento projetado permitirá a execução de estimativas iniciais dos níveis de tarifa que permitirão ao sistema cobrir os custos operacionais" (WRIGHT, HOOK 2008).

De acordo com o BRT, tarifa única é aquela que se aplica em qualquer viagem dentro do sistema (WRIGHT, HOOK 2008). Portanto, observa-se que a tarifa unitária por uso do transporte coletivo, hoje, paga pelo o usuário do sistema em Natal, é feita com base no percurso total realizado pelo ônibus, e não pelo uso que o cidadão faz ao optar pelo transporte em massa. Isso de certa forma, contribui para o uso de carro individual, levando em consideração que o usuário ao optar pelo transporte coletivo por ônibus, para uma viagem de pequeno intervalo pague o mesmo valor como se fizesse o percurso total da linha.

Outro fator que deve ser considerado é qualidade do transporte, como também, a falta de segurança que de certa forma vem causando receio e constrangimento aos usuários que optam pelo transporte coletivo, por exemplo, assaltos (OLIVEIRA, 2003).

O manual de BRT aborda vários tipos de tarifas, dentre elas, o trabalho evidenciou a tarifa única, a tarifa gratuita e a tarifa por distância (WRIGHT, HOOK 2008). A tarifa única, por ser essa aplicada aqui no nosso sistema de transporte coletivo de Natal, e que não tem resolvido o problema dos congestionamentos porque não tem atraído os passageiros dos transportes 
particulares. A gratuita, por ser bastante interessante e ter surtido efeito onde foi implantada por ter atraído usuários dos transportes particulares, esse seria o ponto chave para resolver o problema de congestionamentos nas cidades.

Já a tarifa por distância é bastante utilizada em países desenvolvidos. No entanto, na Tailândia, país em desenvolvimento, esse sistema foi implantado em algumas ferrovias, que de acordo com o manual de BRT Wright e Hook (2008, p. 641) a "estrutura de tarifa por distância espelha melhores os custos operacionais reais e, assim, oferece uma medida mais verdadeira das despesas para os operadores do sistema". Inclusive, São Paulo é citado como exemplo nesse manual, onde, "cobram um preço único nas áreas centrais, mas reverte a um esquema baseado em distância para prosseguir destinos satélites" Wright e Hook (2008, p. 642).

A cidade de Curitiba é um exemplo de mobilidade urbana, onde o sistema implantado com o objetivo de melhorar o trânsito, é visto como um sucesso, tendo os corredores como fator de priorização para o transporte público, que oferece maior fluidez, proporcionando viagens mais rápidas para a população.

De acordo com Lacerda (2006, p. 90):

\begin{abstract}
A efetividade dos corredores exclusivos de ônibus para a solução dos problemas de trânsito urbano é ilustrada pela experiência internacionalmente conhecida de Curitiba, onde foi implantado, a partir da década de 1970, um sistema sobre pneus de média capacidade, com faixas exclusivas, pagamento de passagens anterior ao embarque e plataformas de embarque acima do nível da rua.
\end{abstract}

De fato, essa não seria a premissa deste trabalho, no propósito de redução da circulação de veículos nas ruas das cidades de forma coercitiva, mas de uma conscientização que possa motivar e estimular a opção pelos transportes coletivos, vindo a proporcionará uma melhor qualidade de vida a sociedade em geral.

Agarão et al. (2004, p. 37), diz que:

Contudo, essa problemática social tem se confrontado com os benefícios sociais e ambientais advindos de serviços melhores e mais baratos, capazes de atrair até parcelas consideráveis dos usuários do carro particular. Afinal, o valor básico a ser perseguido no setor, antes de qualquer consideração, é o interesse do usuário e da cidade $[\ldots]$.

Observa-se, que o trânsito é muito desgastante, e por esse motivo, faz-se necessário se pensar em alternativas que possam oferecer aos usuários dos transportes públicos a tranquilidade e a confiança em saber que essa opção trará benefícios, tanto em agilidade no percurso como no cumprimento dos horários pré-estabelecidos junto ao cronograma das concessionárias, prestando serviços com qualidade.

\title{
3 METODOLOGIA
}

A presente pesquisa, quanto aos fins, é considerada como descritiva e exploratória, uma vez que, de modo a entender como a sociedade civil organizada possa influenciar na gestão do transporte público coletivo em Natal na condução dos serviços, e apresenta possíveis alternativas, 
na forma de estudo de caso, descrevendo o processo e explorando aspectos do fenômeno da gestão.

A pesquisa é de caráter exploratório-descritivo, que de acordo com Vergara a pesquisa exploratória por se tratar de estudos com característica de pouco conhecimento acumulado e sistematiza por sua natureza, não podendo comportar hipótese. No entanto, poderão surgir durante ou ao final da pesquisa. Já a pesquisa descritiva tem como características expor determinada população ou fenômeno e também pode estabelecer correlação entre variáveis e definir sua natureza (VERGARA, 2000).

Quanto aos meios, pode ser considerado um estudo qualitativos pois desenvolveu-se um estudo sobre a percepção da gestão do representando do Sindicato das Empresas de Transporte Urbano de Passageiros do município de Natal - SETURN, sobre a eficiência do transporte coletivo por ônibus. Para tanto, foi realizada uma entrevista semiestruturada que consiste identificar a qualidade do transporte público em Natal. Seus dados foram tratados através da técnica de análise de conteúdo, que para (BARDIN, 1977) consiste em um conjunto de técnicas de comunicações, que procuram conhecer aquilo que está por trás das palavras e buscam desvendar outras realidades através das mensagens, e ainda descreve sobre a categorização como uma operação de classificação de elementos constitutivos de um conjunto, por diferenciação e seguidamente reagrupado segundo o gênero, com os critérios previamente definidos. Para efeito desta pesquisa as categorias de análise estão relacionadas com os objetivos específicos abordados anteriormente, conforme apresentado no Quadro 1.

A decisão por utilizar o SETURN como objeto de estudo se deu por esse sindicato ser a representação do terceiro setor na concessão pública do transporte coletivo no Município do Natal, desse modo a visão desse agente revela questões relacionadas as categorias de análise dessa investigação.

\section{ANÁLISE DOS DADOS}

Após a realização da coleta dos dados, a análise da entrevista seguiu um conjunto de técnicas de comunicações, procurando conhecer aquilo que está por trás das palavras, desvendando outras realidades através das respostas obtidas com o representando do Sindicato das Empresas de Transporte Urbano de Passageiros do município de Natal - SETURN, classificando os elementos construtivos para análise.

Quadro 1 - categorização das palavras

\begin{tabular}{|l|l|l|}
\hline \multicolumn{1}{|c|}{ Categoria } & \multicolumn{1}{|c|}{ Significado teórico } & \multicolumn{1}{|c|}{ Significado empírico } \\
\hline $\begin{array}{l}\text { Condições dos transportes } \\
\text { públicos }\end{array}$ & Atender as necessidades dos usuários (FARAH 2001) & $\begin{array}{l}\text { Remuneração do } \\
\text { sistema }\end{array}$ \\
\hline $\begin{array}{l}\text { Padrões de funcionamento } \\
\text { dos transportes }\end{array}$ & Faixas e corredores exclusivos (LACERDA 2006) & $\begin{array}{l}\text { Não tem uma linha } \\
\text { exclusiva }\end{array}$ \\
\hline Eficiência dos transportes & $\begin{array}{l}\text { Oferecer serviços com qualidade a menor custo } \\
\text { (FARAH 2001) }\end{array}$ & $\begin{array}{l}\text { Relação despesas e } \\
\text { receitas }\end{array}$ \\
\hline Parafiscalidade & $\begin{array}{l}\text { A sociedade civil organizada que recebe } \\
\text { contribuições sociais e desenvolve atividade pública } \\
\text { (FERNANDES 2005) }\end{array}$ & $\begin{array}{l}\text { As empresas cumprem } \\
\text { as regras estabelecidas }\end{array}$ \\
\hline
\end{tabular}

Fonte: Elaborado pelos autores 
Com a análise, foi possível identificar algumas características da qualidade dos serviços prestados pelo transporte coletivo por ônibus na cidade do Natal, que transporta uma população usuária de 10.605.433 mês (http://natal.rn.gov.br/sttu2/paginas/ctd-709.html, 2013). Ou seja, número que poderia ser maior, caso os carros particulares ficassem em suas garagens, e assim contribuiria para um trânsito melhor, que na opinião do entrevistado:

É caótico na maioria das capitais do Brasil e do próprio mundo, né. Você vê que inclusive uma coisa interessante, isso vai até servir pra você. Na Alemanha, hoje, se constrói apartamentos sem garagem, que é pro pessoal diminuir a quantidade de utilizações de carros próprios, e poder usar mais o transporte coletivo. Porque o transporte, isso é uma questão de começar, por exemplo, por que que a população usa muito o carro próprio (ENTREVISTADO).

Para o entrevistado, o problema com os transportes púbico está relacionado com o uso dos transportes particulares, uma vez que muitos dos usuários, atualmente, usam seus carros para as atividades cotidianas.

O transporte coletivo da cidade do Natal, ainda é muito deficitário, haja vista que a infraestrutura viária não atende as condições favoráveis de tráfegos, tendo os ônibus de competirem com os automóveis no mesmo espaço:

Hoje o que acontece? Você perguntou aqui a disposição atual atende a população? Não atende por quê? Porque os ônibus ficam amarrados aí no meio do trânsito porque não tem uma linha exclusiva, por consequência, quando param num ponto, quer dizer, há uma superlotação, né! E quando essa superlotação acaba ai vêm os ônibus vazios, aí, inclusive, com prejuízos enormes para empresas de ônibus. Não sei se deu pra notar mais ou menos aí, como é que é, e é difícil não resta dúvida não, mas é difícil começar (ENTREVISTADO).

Dessa forma, observe-se uma quantidade significativa de veículos nas ruas, uma vez que o transporte coletivo urbano não atende satisfatoriamente as necessidades dos usuários, que em muitos casos, perdem muito tempo dentro do ônibus. Além disso, os ônibus não oferecem assento a todos os usuários, sendo que a maior parte do trajeto é feito em pé, haja vista, a indisponibilidade desse tipo de transporte oferecer essa qualidade em conforto, até mesmo, pela estrutura do sistema ficaria inviável. Mas isso seria minimizado com a exclusividade do tráfego para o transporte coletivo, seja através de corredores ou em faixas, pois o tornaria mais rápida.

Em se tratando de melhoria, essa, sendo por parte do poder público, e seguindo o exemplo do que já existe na cidade. Segundo o entrevistado, existem dois pontos de exclusividade para o transporte público coletivo. Primeiro o da Avenida Rio Branco, que é feito por faixa exclusiva à direita da via, e em segundo o da Bernardo Vieira, formado por corredor, isso amenizaria o problema com o trânsito se fosse aplicado em todas as vias destinadas ao transporte público de Natal:

Simplesmente, fazer a exemplo, do que nós já temos aqui em Natal, inclusive em dois pontos: nós temos aqui na Bernardo Vieira e temos aqui na Rio Branco, uma área exclusiva, uma faixa exclusiva para ônibus, onde transita ônibus, taxi com lotação e também ambulâncias, são esses três tipos de veículos que andam, nem os taxis vazios podem andam por aí (ENTREVISTADO). 
Entretanto, o entrevistado faz uma ressalva a Avenida Bernardo Vieira, uma vez que a exclusividade dela se dá de forma central, que assim sendo, não atende inteligentemente, as necessidades do sistema, como a da Avenida Rio Branco que é à direita.

De acordo com o entrevistado, o sindicato vem desenvolvendo trabalho, no propósito de implantar um Sistema de Posicionamento Global no transporte público coletivo da cidade:

Nós estamos trabalhando pra gente ter nesses pontos de paradas, um sistema eletrônico, que você poderá através do seu celular saber mais ou menos qual a distância que o ônibus está do ponto e mais ou menos em que horário ele chegará lá. Considerando todas as variáveis de movimento do trânsito de determinado horário, etc., tudo isso nós temos desenvolvido, ainda não instalado! Porque isso aí depende o quê? Autorização da Secretaria mobilidade, temos investimento que não é uma coisa barata (ENTREVISTADO).

Isso de certa forma é interessante, uma vez que o usuário detenha equipamento tecnológico capaz de operacionalizar o sistema.

O Global Positioning System (GPS) - Sistema de Posicionamento Global, por exemplo, é um sistema que se utiliza de satélites e tem como função básica prestar informações precisas sobre o posicionamento individual no globo terrestre, essa tecnologia pode facilitar o gerenciamento do equipamento de transporte, bem como auxiliar na segurança.

Outro ponto bastante interessante é a integração no transporte público coletivo, essa é uma modalidade que veio a contribuir com usuários que fazem longas viagens, percorrendo vários bairros na cidade, onde, uma única linha não atende seu destino. Desse modo, a integração possibilita que o usuário faça sua viagem, pagando por ela o valor de uma única passagem. No entanto, para o entrevistado essa integração tem sido desvirtuada em decorrência de práticas abusivas, de pessoas que vendem essas passagens eletrônicas, aumentando assim, o número de integração, que de certa forma causa prejuízo para o sistema.

Dá pelo seguinte, agente não pode dizer que benefício ao meu cliente é prejuízo, mas ele é um prejuízo agora porque a tarifa não remunera, eu gostaria que todo mundo que utilizasse e pagasse cada viagem que fizesse, e não fazer duas! Sem contar que, aqui em Natal tem um problema muito sério, que é o valeiro! Que é que o valeiro faz? Você já deve ter visto! Não sei se você anda de ônibus, mas deve ter andado, até mesmo pra fazer seu trabalho. O que o cara faz! A empresa dá o cartão com 100 passagens pro seu funcionário, o cara não usa! Já começo o erro daí. O que ele faz? Vende pro valeiro! Aí o valeiro faz o quê? Tem 42 passagens aqui, que na integração vale o dobro, aí ele chega pra você lá e diz: ei, pra onde vai, pra onde? Há vou... aí tudo bem (ENTREVISTADO).

Com essa situação, observa-se que a integração de certa forma pode causar prejuízo, uma vez que está sendo usada por pessoas que não detém esse direito, haja vista, que está se apropriando de uma concessão feita a empregados de uma determinada empresa.

Entretanto, seguindo o princípio que é usado nos transportes de cargas, aplicando a cobrança por distância, Bowersox e Closs (2001) a prática da integração utilizada, atualmente, praticada nos transportes coletivos na cidade do Natal, não se fará mais necessário, uma vez implantada a tarifa por distância, o usuário embarcará quantas vezes forem necessárias, pagando 
apenas, pela distância que utilizou. No entanto, terá que portar o cartão eletrônico para computar a quantidade de quilômetros percorridos e confirmar o pagamento da tarifa.

O manual de BRT, ver a tarifa por distância com certa preocupação, com relação à população residente na periferia das cidades, que segundo o manual, essa população acabaria arcando com maior custo nos transportes coletivos Wright e Hook (2008). No entanto, aqui no Brasil, o trabalhador recebe auxílio transporte pago pelo empregador (LEI 7.418/1985).

Ainda referente à integração, segundo o entrevistado, os transportes alternativos não participam dessa modalidade, mesmo fazendo parte do sistema de transporte coletivo urbano da cidade, fica de fora, prejudicando assim, os usuários por não terem o mesmo direito de integrar em qualquer modalidade de transporte coletivo existente em Natal:

[...] inclusive vou te dá um dado que talvez você não conheça. Quem apadrinha o sistema alternativo é Seturn. O Seturn hoje instalou os validadores dentro dos carros deles. A gente, inclusive, vende as passagens pra eles. Isso é quase uma imposição! Nós somos concorrentes, mas não somos inimigos. E um sistema de transporte em qualquer lugar inteligente, a integração entre sistema é inevitável. Hoje você vai ter que integrar alternativo com ônibus, com carro, com tudo (ENTREVISTADO).

Entretanto, o entrevistado ressalta a necessidade da integração entre qualquer modalidade de transporte público.

Além de o sindicato atender as demandas das empresas do setor ao qual representa, tem por missão a logística de venda cartões eletrônicos que são utilizados no dia a dia pelos usuários dos transportes públicos e empregados das empresas que atuam no mercado da cidade, contribuindo, dessa forma, para agilidade de embarque.

Dentro da visão logística, o sindicato usa as tecnologias existentes para oferecer atendimentos rápidos na venda dos vales, para isso, se utiliza da Web como mecanismo capaz de acelerar todo o processo de vendas, inclusive dos postos espalhados pela cidade, que são interligados ao sistema:

Sindicato funciona, o seguinte: nós vendemos os vales transportes no nosso sistema de web. O nosso ponto de venda espalhado pela cidade, e todo dinheiro que nós recebemos ele é, nós tiramos, era até ontem, $7 \%$. Hoje dia primeiro de março, vamos começar $6,5 \%$, que é pra manter a estrutura. $O$ resto à gente divide pras empresas, na proporção das suas, prestar seus tamanhos, e como é feita e esta avaliação? A avaliação é feita pelas próprias empresas, que são, são as pessoas jurídicas, né. Vamos dizer assim, proprietários do Seturn. Que a depender dos resultados que elas tenham, elas avaliam a nossa. A nossa relação é comercial com ela (ENTREVISTADO).

Portanto, todo faturamento das empresas, através dos cartões eletrônicos é feito pelo sindicato, que desse total retém para a operacionalização da entidade 6,5\%, e divide o restante entre as empresas prestadoras do serviço de transporte coletivo nesta capital. Entretanto, a avaliação, segundo o entrevistado é feita pelas próprias empresas, ou seja, sindicalizadas ao SETURN que trabalhado ininterruptamente para melhorar todo o sistema de transporte público em Natal. Percebe-se que há uma visão equivocada do entrevistado em relação ao processo 
sindical, uma vez que utiliza o termo "proprietárias", quando na verdade são empresas sindicalizadas a esse sindicato patronal.

Ao falar da missão social, o sindicato, através das empresas que operam o sistema de transporte coletivo da capital, desenvolve uma política de gratuidade baseada na faixa etária e na condição física do usuário, onde são transportados sem custo algum. Para o entrevistado, diante das dificuldades que as empresas estão vivenciando, não está sendo fácil novos investimentos, no entanto a missão social vem sendo desenvolvida da melhor maneira possível:

A nossa missão social é muito grande, não porque não temos que transportar pessoa. Então tá, melhor qualidade possível, e o possível aí vai com um grifo grande, porque a situação tá muito difícil, nós estamos é investindo mais do que recebemos. Nós temos a gratuidade, nós transportamos idosos, nós transportamos deficientes. Só deficientes, hoje, nós temos 8 mil pessoas na cidade que transportado, que são transportados de graça, bastando que ele queira isso, entrar no ônibus e ir embora, tem a carteirinha dele, entrou vai embora (ENTREVISTADO).

Ainda com relação ao papel social desenvolvido pelo SETURN, o entrevistado foi generalista e descreveu uma visão dos Stakeholders, onde se busca obter lucros aos empresários, no entanto, relacionou a relação social, uma imposição do poder municipal:

Bom, é mais ou menos o misto de tudo que falamos até agora, né. O Seturn, ele é um sindicato patronal de empresas de transportes urbanos de Natal, que são empresários, empresários comuns que investem e buscam obter o lucro com isso. A relação social é uma imposição que o governo municipal impõe a gente e nós aceitamos plenamente, que é transportar o que, todos os estudantes com $50 \%$ de desconto, né, as gratuidades e os idosos que a gente transporta com custo zero. (ENTREVISTADO).

Assim, o papel social desenvolvido na entidade, vista pelo entrevistado, seria o dever de transportar alguns usuários pagando tarifa inferior ou a custo zero, enquadrando-se nesse cenário, alunos e idosos. No entanto, a função social deveria está preocupada em atender as necessidades da população usuária do transporte coletivo, e criando mecanismo que pudesse atrair ainda mais pessoas a utilizarem o sistema, primando sempre, pela satisfação e pelo transporte de qualidade, no entanto percebe-se uma concepção mercantilista do setor.

Quanto aos incentivos para o transporte coletivo por parte do poder público, o entrevistado foi taxativo, revelando que não há incentivo, no entanto cita alguns como ISS, que é o Imposto Sobre Serviços por parte da Prefeitura, que oferece uma redução de 4\%. Já Estado, reduz o ICMS, que é o Imposto Sobre Circulação de Mercadoria e Serviços no diesel, e ainda, sobre a titularidade do Estado, o IPVA - Imposto sobre a Propriedade de Veículos Automotores que os ônibus, do sistema transporte coletivo de Natal são isentos:

Zero, pra Natal zero, pro RN zero, não tem porque os subsídios mais comuns que existem é ISS que as prefeituras diminuem de 5 pra $1 \%$, elas também não podem baixar de 1, porque senão, eles são submetidos à lei fiscal, mas até 1 eles podem ir, e o ICMS, há não, eu ia cometendo uma injustiça aqui, e o ICMS, do óleo diesel que eles fazem uma redução também. $O$ único incentivo que nós temos aqui, o único, é que os ônibus de Natal não pagam IPVA, certo, então não tem nenhum 
não. Então o governo estadual, ele não recebe o IPVA nosso, é só o IPVA. Também, porque o seguro DPVAT a gente paga tal, mas o IPVA não, o IPVA a gente tem. Então existe algum incentivo do governo a atividade. O IPVA que eles dão (ENTREVISTADO).

Portanto, existe incentivo por parte dos organismos governamentais, uma vez que as empresas recebem redução em vários impostos, de acordo com a citação acima. Entretanto, o entrevistado argumenta que por parte da Prefeitura, o ISS não poderá ultrapassar essa redução existente devido a Lei Responsabilidade Fiscal.

\section{CONSIDERAÇÕES FINAIS}

Nos últimos anos o uso de transporte particular tem crescido muito. Isso é percebido pelo grande tráfego de veículos nas ruas e avenidas das grandes cidades ou metrópoles, tornando assim, o trânsito mais lento. Em face disso, a procura pelo o transporte público coletivo por ônibus tem diminuído significativamente, despertando o desejo do sindicato das empresas, em elevar os preços da tarifa para cobrir os custos da operacionalização dos serviços.

A tarifa unitária integral ou unitária por uso do transporte coletivo, cobrada ao usuário, é feita com base no percurso total realizado pelo ônibus, e não pelo uso que o cidadão faz ao optar pelo transporte em massa. Isso de certa forma contribui para o uso de carro particular, levando em consideração que o usuário ao optar pelo transporte coletivo por ônibus, para uma viagem de pequeno intervalo pague o mesmo valor como se fizesse o percurso total da linha. Outro fator importante é qualidade do transporte, como também, a falta de segurança que de certa forma vem causando constrangimento aos usuários dos transportes coletivos e incentivando o uso de carros particulares.

Por ser um problema recorrente da sociedade, o congestionamento nas cidades tem sido tema de grande debate. Portanto remete as preocupações que os gestores, principalmente os das áreas de transportes, tentam envolver a sociedade civil organizada, principalmente, o terceiro setor, na busca de soluções que ao longo dos anos possam reverter essa situação na nossa cidade.

Entretanto, observa-se que para manter o equilíbrio financeiro do sistema, precisa-se aumentar a demanda através de mecanismos inovadores e da prestação de serviços com qualidades que atendam satisfatoriamente a necessidade do usuário.

No entanto, o sindicato, enquanto organização que representa as empresas de transportes coletivos da cidade do Natal, com a delegação para operar o sistema de competência do poder público, em que a remuneração se dá através de tarifas que alimentam a estrutura, limita-se, em afirmar que cumpre todas as regras estabelecidas.

Por outro, observa-se a necessidade de investimento na infraestrutura, essa por parte do poder público ou em parceira com o sindicato representante das empresas, no sentido de viabilizar faixas ou corredores exclusivos para o transporte coletivo, oferecendo assim, maior agilidade nas viagens, o que atrairá mais usuários dos transportes particulares, gerando, portanto, maior rentabilidade no sistema.

Portanto, diante da complexidade que é o trânsito e o transporte público, e da necessidade de superá-lo, deixa-se aqui o desejo em despertar o interesse acadêmico na busca de aprofundar 
pesquisas que possam contribuir na melhoria e no entendimento do sistema de transporte coletivo, capaz em atender com maior dignidade a sociedade que faz uso desse modal, e que é tão importante para o desenvolvimento econômico das nações.

\section{REFERÊNCIAS}

1. ARAGÃO, Joaquim et al. Sacudindo a poeira e construindo o novo ciclo de desenvolvimento do transporte público por ônibus. In: SANTOS, Enilson; ARAGÃO Joaquim (organizadores). Transporte em tempos de reforma: estudos sobre o transporte urbano. 2. ed. Natal: Edufrn, 2004.

2. BARDIN, Laurece. Análise de conteúdo. Tradução de Luís Antero Reto e Augusto Pinheiro. Lisboa: Edição 70, 1977.

3. BODMER, Milena; PORTO, Danuza Rangel Macêdo. Marketing no setor de transporte coletivo: uma proposta estratégica. In: SANTOS, Enilson; ARAGÃO Joaquim (organizadores). Transporte em tempos de reforma: estudos sobre o transporte urbano. 2. ed. Natal: Edufrn, 2004.

4. BORGES, Alice Gonzalez. Serviços sociais autônomos - natureza jurídica. Revista Eletrônica de Direito do Estado. Disponível em <http://www.direitodoestado.com.br/artigo/alice-gonzalezborges/servicos-sociais-autonomos-natureza-juridica>. Acessado em: 21 de jan. 2013.

5. BOWERSOX, Donald J.; CLOSS, David J. Logística empresarial: o processo de integração de cadeia e suprimento. São Paulo: Atlas, 2001.

6. BRASIL. Constituição (1988). Constituição República Federativa do Brasil. Brasília: Senado Federal; Centro Gráfico, 1988.

7. BRASIL. Ministério das Cidades. Wright, L.; Hook, W. (2008). Manual de BRT: Guia de Planejamento. Ministério das Cidades, Brasília, Brasil. Disponível em: < http://www.cidades. gov.br/index.php/publicacoes>. Acesso em: 17 de ago. de 2012.

8. BRASIL. Planalto. Lei no 9.637, de 15 de maio de 1998 . Dispõe sobre a qualificação de entidades como organizações sociais. Brasília, 1998. Disponível em: <http://www.planalto. gov.br/ccivil_03/leis/L9637.htm>. Acesso em: 17 de dez. de 2012.

9. BRASIL. Planalto. Lei no 9.790, de 23 de março de 1999. Dispõe sobre a qualificação de pessoas jurídicas de direito privado, sem fins lucrativos, como Organizações da Sociedade Civil de Interesse Público. Brasília, 1999. Disponível em: <http://www.planalto.gov.br/ccivil_03/leis/ L9790.htm>. Acesso em: 17 de dez. de 2012.

10. BRASIL. Planalto. Lei no 9.503, de 23 de setembro de 1997. Brasília, 1999. Disponível em: < http://www.planalto.gov.br/ccivil_03/leis/19503.htm>. Acesso em: 25 de mar. de 2013.

11. BRASIL. Instituto Brasileiro de Geografia e Estatística. Cidades. Disponível em: <http://www. ibge.gov.br/cidadesat/topwindow.htm?1>. Acesso em: 11 de jul. de 2012.

12. BRASIL. Planalto. LEI 7.418, de $\mathbf{1 6}$ de dezembro de 1985. Disponível em: <http://www.planalto .gov.br/ccivil_03/LEIS/L7418.htm>. Acesso em 22 de jun. de 2013.

13. FARAH, Marta Ferreira Santos. Parcerias, novos arranjos institucionais e políticas públicas no nível local de governo. Disponível em: <http://bibliotecadigital.fgv.br/ojs/index.php/rap/ article/view/6364/4949>. Acesso em: 06 de jun. de 2012.

14. FERNANDES, Simone dos Santos Lemos. Teoria da parafiscalidade brasileira. Revista Dialética 
de Direito Tributário no 112. pp.127-133. Disponível em: < http://www.professorsabbag. com.br/arquivos/downloads/1278344725.pdf>. Acesso em: 23 de abr. de 2013.

15. HAIR JR., Joseph F. et al. Fundamentos de métodos de pesquisa em administração. Tradução Lene Belon Ribeiro. Porto Alegre: Bookman, 2005.

16. LACERDA, Sander Magalhães. Precificação de congestionamento e transporte coletivo urbano. Rio de Janeiro: BNDES Setorial, mar. 2006. Disponível em: <http://www.bndes.gov.br/ SiteBNDES/export/sites/default/bndes_pt/Galerias/Arquivos/conhecimento/bnset/set2303. pdf $>$. Acesso em: 25 de fev. de 2013.

17. OLIVEIRA, Andréa Carla Ferreira de. Indicadores associados a acidente de trânsito envolvendo motoristas de ônibus da cidade de natal. 2003. 83 f. Dissertação (Mestrado) Curso de Pós-graduação em Psicologia, Centro de Ciências Humanas, Letras e Artes, Universidade Federal do Rio Grande do Norte, Natal, 2003. Disponível em: <http://repositorio.ufrn.br:8080/jspui/bitstream/123456789/17486/1/AndreaCFO.pdf>. Acesso em: 23 abr. 2013.

18. PREFEITURA MUNICIPAL DO NATAL. Secretaria de Mobilidade Urbana. Disponível em: <http://natal.rn.gov.br/sttu2/paginas/ctd-709.html>. Acesso em jul. de 2012.

19. QUEIROZ Jackelline Rêgo et al. A verticalização do bairro de lagoa nova em Natal-RN: as causas dessa crescente transformação territorial. Disponível em: <http://connepi2009.ifpa. edu.br/connepi-anais/artigos/193_3628_1619.pdf>. Acesso em: 23 de mar. De 2013.

20. TOMEI, Patrícia Amélia; FORTUNATO, Graziela. A solidão no poder nas organizações. Disponível em: < http://www.revistaoes.ufba.br/viewarticle.php?id=488\&layout=abstract>. Acesso em: 26 de out. de 2012.

21. VERGARA, Sylvia Constant. Projetos e relatórios de pesquisa em administração. São Paulo: Atlas, 2000. 